\title{
A Voltage Gain-Controlled Modified CFOA And Its Application in Electronically Tunable Four-Mode All-Pass Filter Design
}

\author{
Norbert Herencsar, Jaroslav Koton, Abhirup Lahiri, Bilgin Metin, and Kamil Vrba
}

\begin{abstract}
This paper presents a new active building block (ABB) called voltage gain-controlled modified current feedback amplifier (VGC-MCFOA) based on bipolar junction transistor technology. The versatility of the new ABB is demonstrated in new first-order all-pass filter structure design employing single VGC-MCFOA, single grounded capacitor, and three resistors. Introduced circuit provides all four possible transfer functions at the same configuration, namely current-mode, transimpedancemode, transadmittance-mode, and voltage-mode. The pole frequency of the circuit can be easily tuned by means of DC bias currents. The theoretical results are verified by SPICE simulations based on bipolar transistor arrays AT\&T ALA400CBIC-R process parameters.
\end{abstract}

Keywords-Voltage gain-controlled modified CFOA, MCFOA, electronically tunable filter, four-mode circuit, all-pass filter.

\section{INTRODUCTION}

After the second-generation current conveyor (CCII) was introduced by Sedra and Smith in 1970 [1], it became the most versatile active building block (ABB) used for analog signal processing and the is basic ABB of many other active elements such as the composite current conveyor [2] done by an interconnection of two CCIIs, which was recently introduced as modified current feedback operational amplifier (MCFOA) [3]-[7] or the conventional CFOA [8] (CCII followed by unity gain voltage buffer - UGVB). It should be noted that, the MCFOA is different from the conventional CFOA defined in [8], since the W terminal current of the MCFOA is copied to the $\mathrm{Y}$ terminal in the opposite direction. However, it is well known that the Y-terminal current of the conventional CFOA is equal to zero. Short list of additional CCII-based ABBs is the following: the second-generation current-controlled conveyor (CCCII) [9], where the intrinsic resistance of X-terminal can be tuned, the differential difference CC (DDCC) [10] and its more versatile derivative the so-called universal current conveyor (UCC) [11]-[14], the dual-X CCII (DXCCII) [15], which is an interconnection of CCII and inverting CCII

N. Herencsar, J. Koton, and K. Vrba are with the Department of Telecommunications, Faculty of Electrical Engineering and Communication, Brno University of Technology, Purkynova 118, 61200 Brno, Czech Republic (phone: +420-541149190; fax: +420-541149192; e-mails: \{herencsn, koton, vrbak\}@feec.vutbr.cz; web: http://publicationslist.org/herencsar).

A. Lahiri is with the 36-B, J and $\mathrm{K}$ Pocket, Dilshad Garden, Delhi-110095, India (e-mail: lahiriabhirup@yahoo.com; http://www.publicationslist.org/lahiriabhirup).

B. Metin is with the Department of Management Information Systems, Bogazici University, Hisar Campus, 34342 Bebek-Istanbul, Turkey (e-mail: bilgin.metin@boun.edu.tr; http://www.mis.boun.edu.tr/metin/).

Manuscript received October XX, 2012; revised Month DD, YYYY. in which the Y-terminal is joined, the current differencing buffered amplifier (CDBA) [16] employing current differencing unit (CDU) based on two CCIIs and UGVB, or the universal voltage conveyor (UVC) [17] based on two CCIIs and differential UGVB.

Recently the further research has been focused on CCIIbased ABBs employing operational transconductance amplifier (OTA) [18] at their output stage. Probably the most known active element from this group is the current differencing transconductance amplifier (CDTA) [19], but other versatile elements such as the current-conveyor transconductance amplifier (CCTA) [20], where CCII is followed by an OTA, the differential-input buffered and transconductance amplifier (DBTA) [21] in which an interconnection of two CCIIs are followed by UGVB and OTA, the current follower transconductance amplifier (CFTA) [22], which employs a CCII with grounded Y-terminal and an OTA, the current backward transconductance amplifier (CBTA) [23], which is a specific interconnection of CCII and OTA, or the z-copy currentcontrolled current inverting transconductance amplifier (ZCCCCITA) [24] have also received considerable attention.

For easy tunability of the circuit parameters using electrical signals by either voltage and/or current and to increase the universality of the conventional CCII, the electronically-tunable CCII (ECCII) [25], [26], programmable current amplifier (PCA) [27], K-gain CCII [28], the voltage and current gain CCII (VCG-CCII) [29], and the variable gain current conveyor (VGCCII) [30] were introduced.

In this paper we present a novel $\mathrm{ABB}$ called voltage gain-controlled modified current-feedback operational amplifier (VGC-MCFOA). The VGC-MCFOA joins the voltage gain control feature of the VCG-CCII in the conventional MCFOA [3]-[7]. To demonstrate the usefulness of the VGC-MCFOA, a new first-order all-pass filter (AFP) structure is proposed, which operates in current-mode (CM), transimpedance-mode (TIM), transadmittance-mode (TAM), and voltage-mode (VM), respectively. To prove the theoretical analysis, SPICE simulations based on bipolar transistor arrays AT\&T ALA400-CBIC-R process parameters are given.

\section{Circuit Description}

The voltage gain-controlled modified current feedback operational amplifier (VGC-MCFOA) is a five-terminal ABB and its circuit symbol is shown in Fig. 1 (a). Compared to the conventional MCFOA presented in [3]-[7], its voltage transfer 


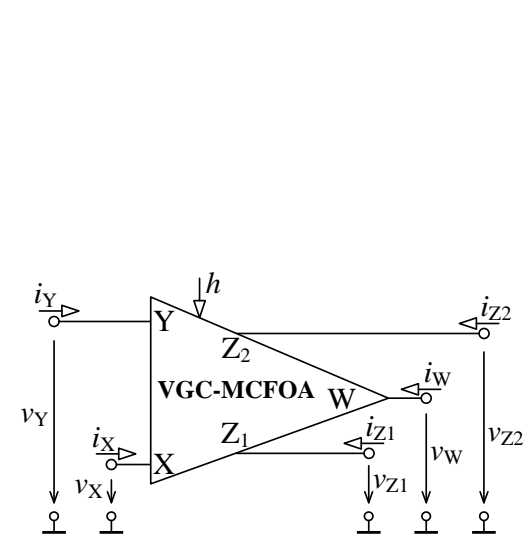

(a)

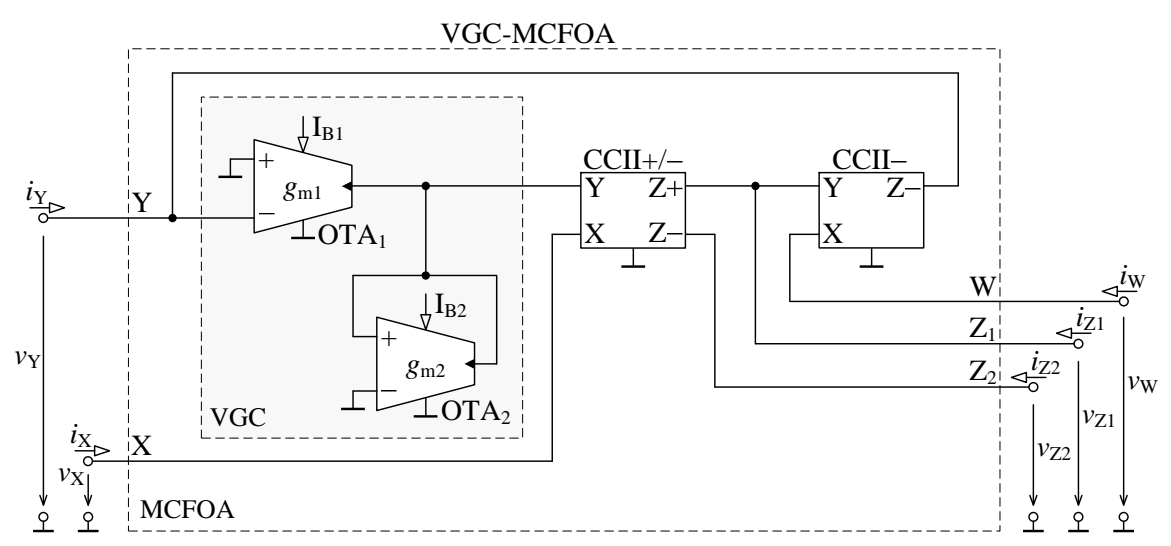

(b)

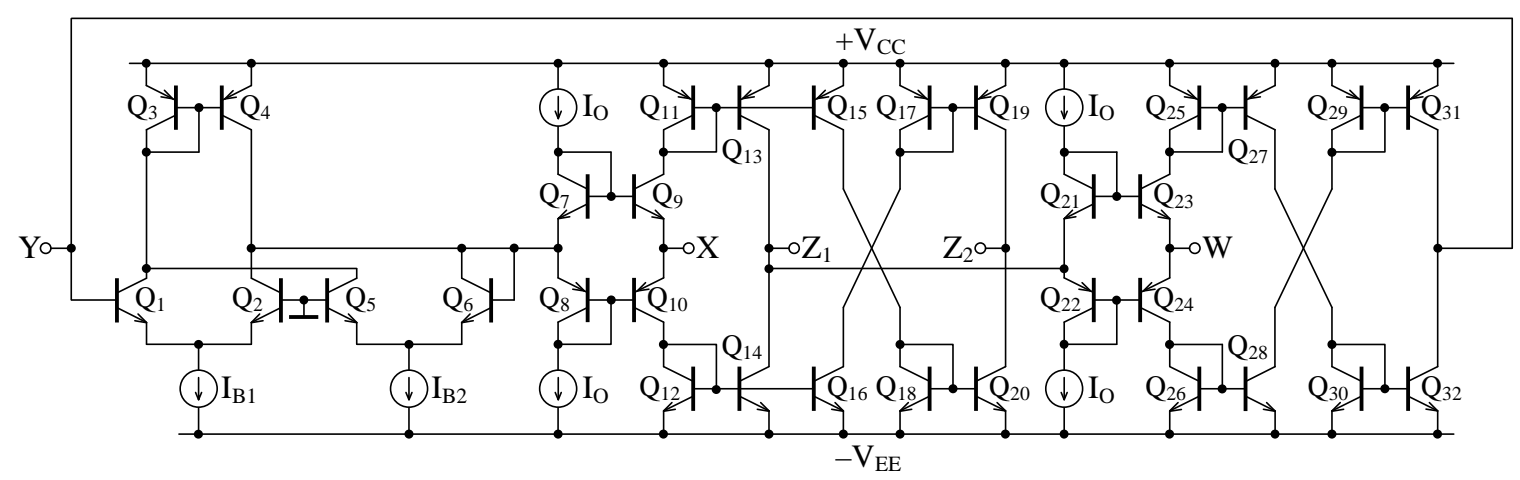

(c)

Fig. 1. Bipolar implementation of VGC-MCFOA

from the $\mathrm{Y}$ to $\mathrm{X}$ terminal can be easily electronically tuned by means of the voltage gain $h$. Hence, the relations between the individual terminals of the VGC-MCFOA can be described by the following hybrid matrix:

$$
\left[\begin{array}{c}
i_{\mathrm{Y}} \\
v_{\mathrm{X}} \\
i_{\mathrm{Z} 1} \\
i_{\mathrm{Z} 2} \\
v_{\mathrm{W}}
\end{array}\right]=\left[\begin{array}{ccccc}
0 & 0 & 0 & 0 & -\alpha_{1} \\
h \beta_{1} & 0 & 0 & 0 & 0 \\
0 & \alpha_{2} & 0 & 0 & 0 \\
0 & -\alpha_{3} & 0 & 0 & 0 \\
0 & 0 & \beta_{2} & 0 & 0
\end{array}\right]\left[\begin{array}{c}
v_{\mathrm{Y}} \\
i_{\mathrm{X}} \\
v_{\mathrm{Z} 1} \\
v_{\mathrm{Z} 2} \\
i_{\mathrm{W}}
\end{array}\right]
$$

The frequency-dependent non-ideal current gains $\alpha_{j}$ for $j=\{1,2,3\}$ and voltage gains $\beta_{k}$ for $k=\{1,2\}$ are ideally equal to unity. Using a single-pole model [4], they can be defined as:

$$
\begin{aligned}
& \alpha_{j}(s)=\frac{\alpha_{o j}}{1+s \tau_{\alpha_{j}}}, \\
& \beta_{k}(s)=\frac{\beta_{o k}}{1+s \tau_{\beta_{k}}},
\end{aligned}
$$

where $\alpha_{o j}$ and $\beta_{o k}$ are DC current and voltage gains of the element, respectively. The bandwidths $1 / \tau_{\alpha_{j}}$ and $1 / \tau_{\beta_{k}}$ on the order of a few gigarad/s in current technologies are ideally equal to infinity. At low and medium frequencies i.e., $f \ll$ $(1 /(2 \pi)) \times \min \left\{1 / \tau_{\alpha_{j}}, 1 / \tau_{\beta_{k}}\right\}$, Eqs. 22 and 33 turn to:

$$
\begin{aligned}
& \alpha_{j}(s) \cong \alpha_{o j}=1-\varepsilon_{\alpha_{i j}}, \\
& \beta_{k}(s) \cong \beta_{o k}=1-\varepsilon_{\beta_{v k}},
\end{aligned}
$$

where $\varepsilon_{\alpha_{i j}}$ and $\varepsilon_{\beta_{v k}}$ are the current and voltage tracking errors, whereas $\left|\varepsilon_{\alpha_{i j}}\right| \ll 1$ and $\left|\varepsilon_{\beta_{v k}}\right| \ll 1$, respectively.

The basic idea for implementation of the proposed VGCMCFOA is shown in Fig. 1 (b), where the OTA 1 and OTA 2 are used to control the voltage gain $h$ and two $\mathrm{CCII}+/$ represent the conventional MCFOA. Subsequently, the bipolar implementation of the VGC-MCFOA is shown in Fig. 11. (c). The voltage gain control stage is formed by two simple differential pair amplifiers (transistors $Q_{1}-Q_{6}$ ) and transistors $Q_{7}-Q_{32}$ form the two CCII+/- based MCFOA, respectively. Here it is worth mentioning that the voltage gain control of VCG-CCII [29] was implemented using the same technique. For the implementation in Fig. 11.b) the voltage gain $h$ can be expressed as:

$$
h=\frac{g_{m_{1,2}}}{g_{m_{5,6}}},
$$

where $g_{m_{1,2}}=\frac{I_{\mathrm{B} 1}}{2 V_{\mathrm{T}}}$ and $g_{m_{5,6}}=\frac{I_{\mathrm{B} 2}}{2 V_{\mathrm{T}}}$. Here, the $V_{\mathrm{T}}$ is the thermal voltage (approximately $26 \mathrm{mV}$ at $27^{\circ} \mathrm{C}$ ) and the $I_{\mathrm{B} 1}$ and $I_{\mathrm{B} 2}$ are control currents adjusting the transconductances $g_{m_{1,2}}$ and $g_{m_{5,6}}$, respectively. Therefore, the voltage gain $h$ in (6) can be given as:

$$
h=\frac{I_{\mathrm{B} 1}}{I_{\mathrm{B} 2}} .
$$

From (7) it is obvious that the proposed VGC-MCFOA can be easily adjusted electronically by either $I_{\mathrm{B} 1}$ and/or $I_{\mathrm{B} 2}$ currents. 


\section{Proposed All-Pass Filter}

\section{A. Ideal Case Study}

The proposed four-mode APF is shown in Fig. 2. Considering the ideal VGC-MCFOA (i.e. $\alpha_{j}$ and $\beta_{k}$ are unity), based on the input selected two following cases can be considered:

Case I: If $I_{i n 1}=I_{i n 2}=I_{i n}, V_{i n}=0$ (grounded), and assuming $R_{2}=R_{3}=R$, then we can obtain the following transfer functions (TFs):

$$
T_{\mathrm{CM}}(s)=\frac{I_{\text {out }}}{I_{\text {in }}}=\frac{s C R_{1}-h}{s C R_{1}+h}=\frac{I_{\mathrm{B} 2} s C R_{1}-I_{\mathrm{B} 1}}{I_{\mathrm{B} 2} s C R_{1}+I_{\mathrm{B} 1}}
$$

$$
T_{\mathrm{TIM}}(s)=\frac{V_{\text {out }}}{I_{\text {in }}}=R \cdot \frac{s C R_{1}-h}{s C R_{1}+h}=R \cdot \frac{I_{\mathrm{B} 2} s C R_{1}-I_{\mathrm{B} 1}}{I_{\mathrm{B} 2} s C R_{1}+I_{\mathrm{B} 1}} .
$$

Case II: If the input of the APF is $V_{i n}, I_{i n 1}=I_{i n 2}=0$, and assuming $R_{1}=R_{2}=R$, then for the circuit the following TFs can be obtained:

$$
T_{\mathrm{TAM}}(s)=\frac{I_{\text {out }}}{V_{\text {in }}}=-\frac{1}{R} \cdot \frac{s C R_{3}-h}{s C R_{3}+h}=-\frac{1}{R} \cdot \frac{I_{\mathrm{B} 2} s C R_{3}-I_{\mathrm{B} 1}}{I_{\mathrm{B} 2} s C R_{3}+I_{\mathrm{B} 1}},
$$$$
T_{\mathrm{VM}}(s)=\frac{V_{\text {out }}}{V_{\text {in }}}=-\frac{s C R_{3}-h}{s C R_{3}+h}=-\frac{I_{\mathrm{B} 2} s C R_{3}-I_{\mathrm{B} 1}}{I_{\mathrm{B} 2} s C R_{3}+I_{\mathrm{B} 1}} .
$$

Thus, from Eqs. (8)-11 it is seen that by suitable selection of input and output all four possible modes, i.e. current, transimpedance-, transadmittance-, and voltage-mode firstorder APF can be realized with the same circuit topology.

The phase responses of TFs in (8) and (9) are calculated as follows:

$$
\begin{aligned}
& \varphi_{\mathrm{CM}}(\omega)=\varphi_{\mathrm{TIM}}(\omega)=180^{\circ}-2 \operatorname{arctg}\left(\frac{1}{h} \cdot \omega C R_{1}\right)= \\
& =180^{\circ}-2 \operatorname{arctg}\left(\frac{I_{\mathrm{B} 2}}{I_{\mathrm{B} 1}} \cdot \omega C R_{1}\right),
\end{aligned}
$$

and phase responses of TFs in 10 and $(11)$ are given as:

$$
\begin{aligned}
& \varphi_{\mathrm{TAM}}(\omega)=\varphi_{\mathrm{VM}}(\omega)=-2 \operatorname{arctg}\left(\frac{1}{h} \cdot \omega C R_{3}\right)= \\
& =-2 \operatorname{arctg}\left(\frac{I_{\mathrm{B} 2}}{I_{\mathrm{B} 1}} \cdot \omega C R_{3}\right) .
\end{aligned}
$$

Hence, the phases of TFs in $(8)$ and $(9)$ alter from $180^{\circ}$ to $0^{\circ}$ while according to $(10)$ and $(11)$ the phase shift change between $0^{\circ}$ to $-180^{\circ}$, respectively.

Consequently, the zero $\left(\omega_{z}\right)$ and pole $\left(\omega_{p}\right)$ frequencies of all four TFs can be found as:

$$
\begin{gathered}
\omega_{(\mathrm{CM}, \mathrm{TIM}) z}=\omega_{(\mathrm{CM}, \mathrm{TIM}) p}=h \cdot \frac{1}{C R_{1}}=\frac{I_{\mathrm{B} 1}}{I_{\mathrm{B} 2}} \cdot \frac{1}{C R_{1}}, \\
\omega_{(\mathrm{TAM}, \mathrm{VM}) z}=\omega_{(\mathrm{TAM}, \mathrm{VM}) p}=h \cdot \frac{1}{C R_{3}}=\frac{I_{\mathrm{B} 1}}{I_{\mathrm{B} 2}} \cdot \frac{1}{C R_{3}} .
\end{gathered}
$$

From Eqs. (14) and (15) it is clearly seen that the pole/zero frequency values can be easily tuned by means of the bias currents $I_{\mathrm{B} 1}$ and/or $I_{\mathrm{B} 2}$.

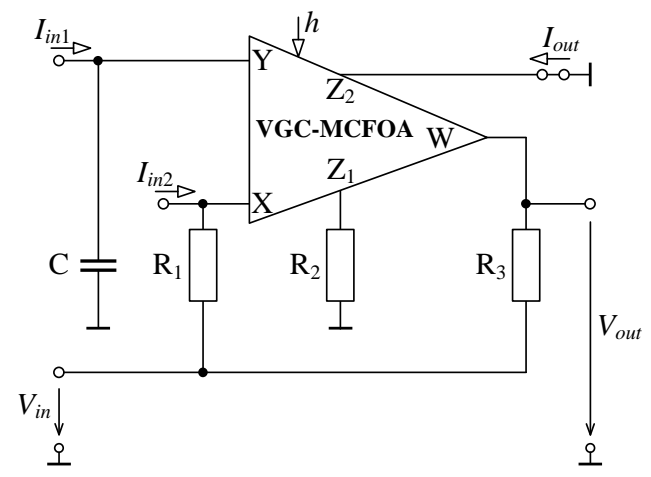

Fig. 2. Proposed electronically tunable all-pass filter using VGC-MCFOA

\section{B. Non-Ideal Analysis}

Taking into account non-idealities of the VGC-MCFOA, TFs (8) and (9) in Case $I$ of the filter convert to:

$$
\begin{gathered}
T_{\mathrm{CM}}(s)=\frac{I_{\text {out }}}{I_{\text {in }}}=\alpha_{3} R_{3} \cdot \frac{s C R_{1}-\beta_{1} h}{s C R_{1} R_{3}+\alpha_{1} \alpha_{2} \beta_{1} \beta_{2} h R_{2}}= \\
=\alpha_{3} R_{3} \cdot \frac{I_{\mathrm{B} 2} s C R_{1}-I_{\mathrm{B} 1} \beta_{1}}{I_{\mathrm{B} 2} s C R_{1} R_{3}+I_{\mathrm{B} 1} \alpha_{1} \alpha_{2} \beta_{1} \beta_{2} R_{2}}, \\
T_{\mathrm{TIM}}(s)=\frac{V_{\text {out }}}{I_{\text {in }}}=\frac{\alpha_{2} \beta_{2} R_{2} R_{3} \cdot\left(s C R_{1}-h \beta_{1}\right)}{s C R_{1} R_{3}+\alpha_{1} \alpha_{2} \beta_{1} \beta_{2} h R_{2}}= \\
=\frac{\alpha_{2} \beta_{2} R_{2} R_{3} \cdot\left(I_{\mathrm{B} 2} s C R_{1}-I_{\mathrm{B} 1 \beta_{1}}\right)}{I_{\mathrm{B} 2} s C R_{1} R_{3}+I_{\mathrm{B} 1} \alpha_{1} \alpha_{2} \beta_{1} \beta_{2} R_{2}}
\end{gathered}
$$

and non-ideal phase responses from TFs $(16)$ and $(17)$ can be expressed as:

$$
\begin{aligned}
& \varphi_{\mathrm{CM}}(\omega)=\varphi_{\mathrm{TIM}}(\omega)=180^{\circ}-\operatorname{arctg}\left(\frac{I_{\mathrm{B} 2}}{I_{\mathrm{B} 1}} \cdot \frac{\omega C R_{1}}{\beta_{1}}\right)- \\
& -\operatorname{arctg}\left(\frac{I_{\mathrm{B} 2}}{I_{\mathrm{B} 1}} \cdot \frac{\omega C R_{1} R_{3}}{\alpha_{1} \alpha_{2} \beta_{1} \beta_{2} R_{2}}\right) .
\end{aligned}
$$

The zero and pole frequencies in Eq. (14) change to:

$\omega_{(\mathrm{CM}, \mathrm{TIM}) z}=\frac{I_{\mathrm{B} 1}}{I_{\mathrm{B} 2}} \cdot \frac{\beta_{1}}{C R_{1}}, \omega_{(\mathrm{CM}, \mathrm{TIM}) p}=\frac{I_{\mathrm{B} 1}}{I_{\mathrm{B} 2}} \cdot \frac{\alpha_{1} \alpha_{2} \beta_{1} \beta_{2} R_{2}}{C R_{1} R_{3}}$.

From Eq. (19), the active and passive sensitivities of zero and pole frequencies are given as:

$$
S_{I_{\mathrm{B} 1}, \beta_{1}}^{\omega_{(\mathrm{CM}, \mathrm{TIM}) z}}=-S_{I_{\mathrm{B} 2}, C, R_{1}}^{\omega_{(\mathrm{CM}, \mathrm{TIM}) z}}=1, S_{\alpha_{1}, \alpha_{2}, \alpha_{3}, \beta_{2}, R_{2}, R_{3}}^{\omega_{(\mathrm{CM}, \mathrm{TIM}) z}}=0,
$$

$S_{I_{\mathrm{B} 1}, \alpha_{1}, \alpha_{2}, \beta_{1}, \beta_{2}, R_{2}}^{\omega_{(\mathrm{CM}, \mathrm{TM}) p}}=-S_{I_{\mathrm{B} 2}, C, R_{1}, R_{3}}^{\omega_{(\mathrm{CM}, \mathrm{TI})}}=1, S_{\alpha_{3}}^{\omega_{(\mathrm{CM}, \mathrm{TIM}) p}}=0$,

and it is evident that the sensitivities of active parameters and passive components for $\omega_{\text {(CM,TIM }) z}$ and $\omega_{\text {(CM,TIM })}$ are at maximum unity in relative amplitude. The same study can also be done for the Case $I I$ with similar results.

\section{Simulation RESUlts}

First, the proposed VGC-MCFOA in Fig. 11(c) has been further investigated in SPICE software. In the design the transistor model parameters NR100N (NPN) and PR100N (PNP) of bipolar arrays ALA400-CBIC-R from AT\&T were used 


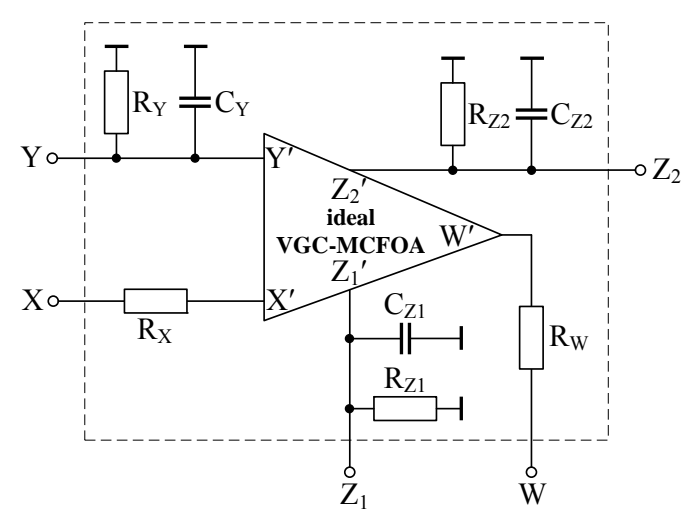

Fig. 3. Model of the VGC-MCFOA including parasitic elements

TABLE I

Parameters of VGC-MCFOA SHOWN IN Fig. 1. C) (Note: \# AT $h=1$ )

\begin{tabular}{ll}
\hline \hline Parameters & Values \\
\hline$i_{\mathrm{Y}} / i_{\mathrm{W}}$ gain $\left(\alpha_{1}\right)$ & 1.001 \\
$v_{\mathrm{X}} / v_{\mathrm{Y}}$ gain $\left(\beta_{1}\right)^{\#}$ & 0.995 \\
$i_{\mathrm{Z} 1} / i_{\mathrm{X}}$ gain $\left(\alpha_{2}\right)$ & 0.982 \\
$i_{\mathrm{Z} 2} / i_{\mathrm{X}}$ gain $\left(\alpha_{3}\right)$ & 1.001 \\
$v_{\mathrm{W}} / v_{\mathrm{Z} 1}$ gain $\left(\beta_{2}\right)$ & 0.999 \\
\hline$i_{\mathrm{Y}} / i_{\mathrm{W}} f_{-3 \mathrm{~dB}}$ & $49.16 \mathrm{MHz}$ \\
$v_{\mathrm{X}} / v_{\mathrm{Y}} f_{-3 \mathrm{~dB}} \#$ & $108.15 \mathrm{MHz}$ \\
$i_{\mathrm{Z} 1} / i_{\mathrm{X}} f_{-3 \mathrm{~dB}}$ & $89.22 \mathrm{MHz}$ \\
$i_{\mathrm{Z} 2} / i_{\mathrm{X}} f_{-3 \mathrm{~dB}}$ & $67.34 \mathrm{MHz}$ \\
$v_{\mathrm{W}} / v_{\mathrm{Z} 1} f_{-3 \mathrm{~dB}}$ & $879.47 \mathrm{MHz}$ \\
\hline$R_{\mathrm{Y}}$ & $55.35 \mathrm{k} \Omega$ \\
$C_{\mathrm{Y}}$ & $1.919 \mathrm{pF}$ \\
$R_{\mathrm{X}}$ & $42.01 \Omega$ \\
$R_{\mathrm{W}}$ & $36.96 \Omega$ \\
$R_{\mathrm{Z} 1}$ & $94.31 \mathrm{k} \Omega$ \\
$C_{\mathrm{Z} 1}$ & $2.047 \mathrm{pF}$ \\
$R_{\mathrm{Z} 2}$ & $97.61 \mathrm{k} \Omega$ \\
$C_{\mathrm{Z} 2}$ & $1.272 \mathrm{pF}$ \\
\hline \hline
\end{tabular}

[31]. The DC supply voltages are $+V_{\mathrm{CC}}=-V_{\mathrm{EE}}=2.5 \mathrm{~V}$. Bias current $I_{\mathrm{O}}=400 \mu \mathrm{A}$ has been chosen and $I_{\mathrm{B} 1}, I_{\mathrm{B} 2}$ were set to $101 \mu \mathrm{A}$ and $100 \mu \mathrm{A}$, respectively, to obtain voltage gain $h=1$ precisely. The maximum values of terminal voltages and terminal currents without producing significant distortion were determined to be $\pm 106.7 \mathrm{mV}$ and $\pm 16.23 \mathrm{~mA}$, respectively. Evaluated DC current and voltage gains, $f_{-3 \mathrm{~dB}}$ frequencies of transfers, and values of the $\mathrm{X}$ and $\mathrm{W}$ terminal parasitic resistances (in series) and $\mathrm{Z}$ and $\mathrm{Y}$ terminal parasitic resistances and capacitances (in parallel) shown in Fig. 3 are given in Table I. The total power dissipation of the proposed VGC-MCFOA was found to be $23.1 \mathrm{~mW}$.

Simulated voltage gain $h$ responses between $\mathrm{Y}$ and $\mathrm{X}$ terminals is demonstrated in Fig. 4. In case of (A), the external bias current $I_{\mathrm{B} 1}$ has been varied in large interval from $10 \mu \mathrm{A}$ to $1 \mathrm{~mA}$ (equal to gain $h=0.1$ to 10 ) at constant $I_{\mathrm{B} 2}=100 \mu \mathrm{A}$. From Fig. 4 it can be clearly seen that due to the above mentioned non-idealities of the VGC-MCFOA, the obtained voltage gain is in reduced range $0.101 \div 8.71$. Hence, to overcome the the large variation of control current $I_{\mathrm{B} 1}$ and simultaneously obtain the same gain range i.e. $h=0.1$ to 10 , the control current $I_{\mathrm{B} 1}$ has been varied in reduced interval

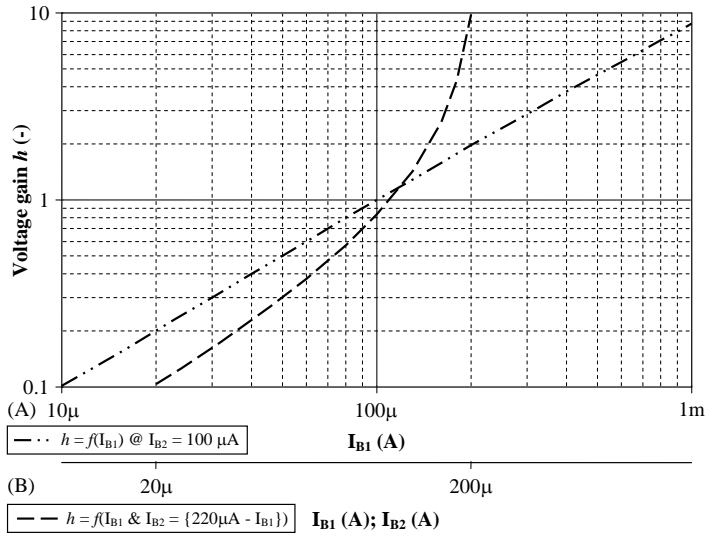

Fig. 4. Voltage gain $h$ responses vs. applied bias currents

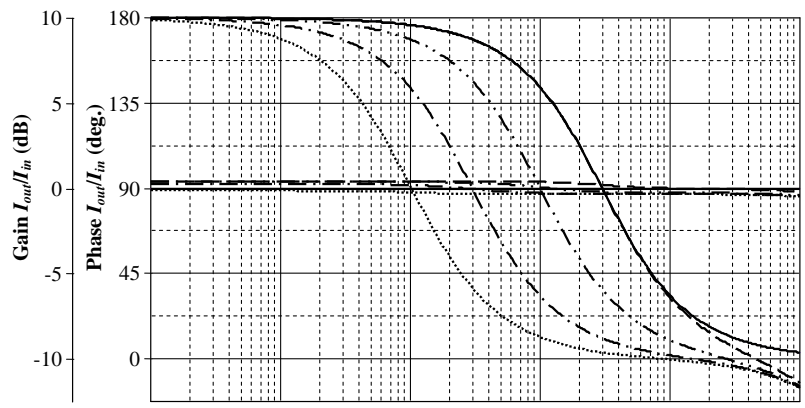

(a)

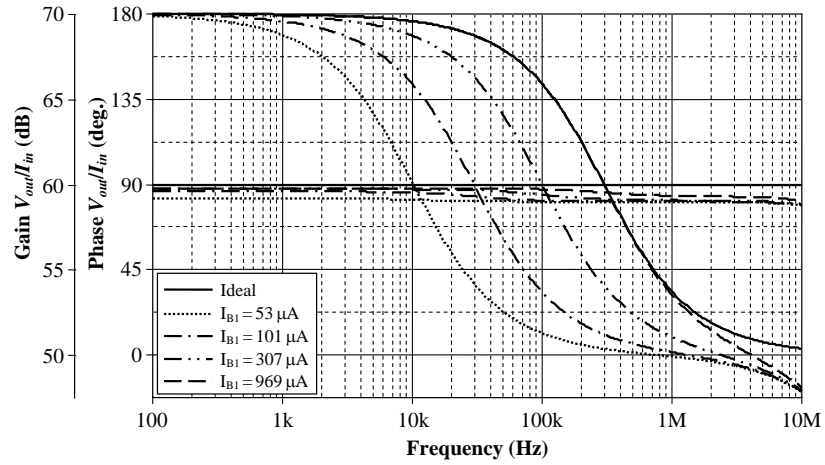

(b)

Fig. 5. Electronical tunability of the pole frequency by bias current $I_{\mathrm{B} 1}$ based on case (A) at constant $I_{\mathrm{B} 2}=100 \mu \mathrm{A}$ : (a) current-mode, (b) transimpedancemode first-order APF responses

from $20 \mu \mathrm{A}$ to $200 \mu \mathrm{A}$ together with $I_{\mathrm{B} 2}$ according to $\mathrm{Eq}$ $\left\{220 \mu \mathrm{A}-I_{\mathrm{B} 1}\right\}$. In this case (B), the obtained voltage gain is in range $0.102 \div 9.869$, which is much closer to the theoretical one.

Using the bipolar implementation of the VGC-MCFOA the proposed APF from Fig. 2 has also been simulated in the SPICE software. The ideal and simulated gain and phase responses and electronical tunability of both current- and transimpedance-mode transfers based on case (A) discussed above i.e. by the bias current $I_{\mathrm{B} 1}$ at constant $I_{\mathrm{B} 2}=100 \mu \mathrm{A}$, are demonstrated in Fig. 5. In the simulations the passive element values were selected as $C=5 \mathrm{nF}, R_{1}=R_{2}=R_{3}=$ $1 \mathrm{k} \Omega$ and the voltage gain $h$ has been varied as $h=\{0.53 ; 1$; 


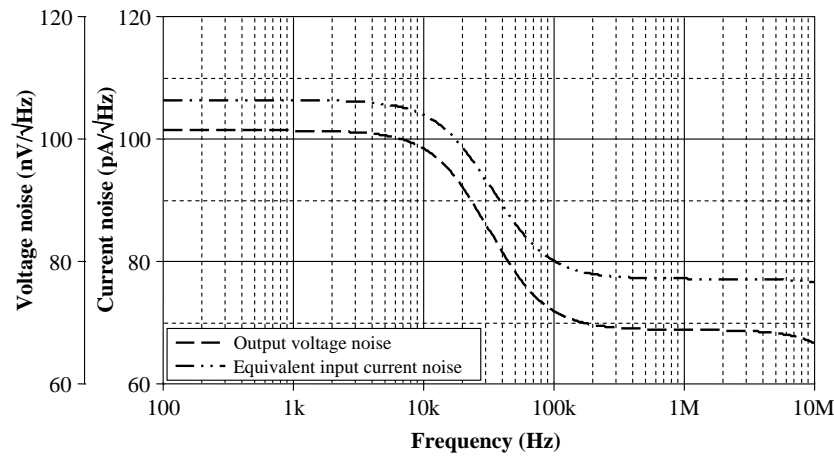

Fig. 6. Output and equivalent input noise variations vs. frequency at $h=1$ $\left(f_{0}=29.9 \mathrm{kHz}\right)$ for the transimpedance-mode first-order APF response

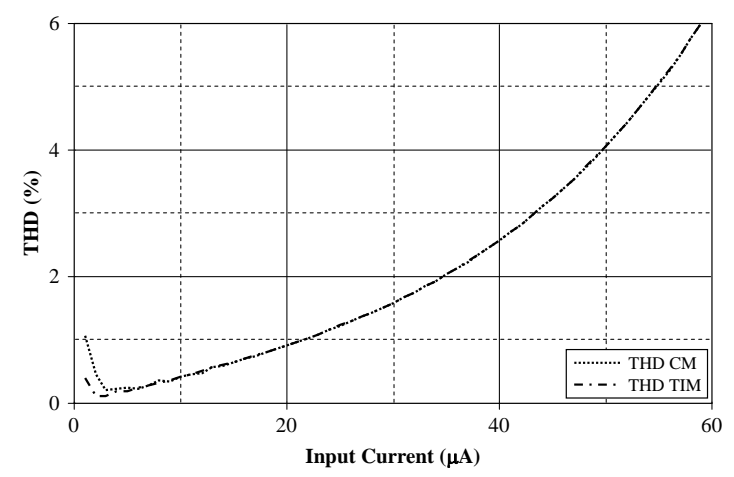

Fig. 7. THD variation of the proposed APF for both currentand transimpedance-mode responses against applied input current at $f_{0}=29.9 \mathrm{kHz}$

$2.95 ; 8.46\}$ to set the pole frequency of the proposed circuit as $f_{0} \approx\{10.2 ; 29.9 ; 100 ; 300\} \mathrm{kHz}$. Using the INOISE and ONOISE statements, the input and output noise behavior with respect to frequency has also been simulated, as it is shown in Fig. 6. The output noise and equivalent input noise at pole frequency $\left(f_{0} \cong 29.9 \mathrm{kHz}\right)$ were found as $86.13 \mathrm{nV} / \sqrt{\mathrm{Hz}}$ and $93.38 \mathrm{pA} / \sqrt{\mathrm{Hz}}$, respectively. The THD variation for both responses with respect to amplitude of the applied sinusoidal input current at pole frequency of $29.9 \mathrm{kHz}$ (filter parameter: $\left.I_{\mathrm{B} 1}=101 \mu \mathrm{A}\right)$ is shown in Fig. 7 An input with the amplitude of $30 \mu \mathrm{A}$ yields for both responses THD values of $1.59 \%$. From the simulations it is evident that the gain and phase characteristics of the filter are in good agreement with theory and the deviations are caused by the non-idealities of the active element used.

\section{CONCLUSION}

In this paper, a novel ABB called voltage gain-controlled MCFOA, which joins the voltage gain control feature of the voltage and current gain CCII in the conventional MCFOA. The usefulness of the tunable feature in the introduced VGCMCFOA is demonstrated in four-mode first-order all-pass filter design. Since the capacitor in the circuit is grounded, the proposed filter is attractive for integration. The pole frequency can successfully be tuned in wide frequency range by means of external bias currents. The SPICE simulations confirm the theoretical assumptions.

\section{ACKNOWLEDGMENT}

Ing. Norbert Herencsár, Ph.D. was supported by the project CZ.1.07/2.3.00/30.0039 of Brno University of Technology. Research described in this paper was also in part supported by the project SIX CZ.1.05/2.1.00/03.0072 from the operational program Research and Development for Innovation, BUT Fund No. FEKT-S-11-15, and Czech Science Foundation projects under No. P102/11/P489, P102/10/P561, P102/09/1681.

A preliminary version of this paper has been presented at the 13th Int. Conf. on Optimization of Electrical and Electronic Equipment (OPTIM 2012) [32].

\section{REFERENCES}

[1] A. S. Sedra and K. C. Smith, "A second-generation current conveyor and its applications," IEEE Trans. Circuit Theory, vol. 17, no. 1, pp. 132-134, 1970.

[2] K. C. Smith and A. S. Sedra, "Realization of the Chua family of new nonlinear network elements using the current conveyor," IEEE Trans. Circuit Theory, vol. 17, pp. 137-139, 1970.

[3] E. Yuce, "On the implementation of the floating simulators employing a single active device," AEU-Int. J. Electron. and Commun., vol. 61, no. 7, pp. 453-458, 2007.

[4] E. Yuce and S. Minaei, "A modified CFOA and its applications to simulated inductors, capacitance multipliers, and analog filters," IEEE Trans. Circuits and Systems-I, vol. 55, no. 1, pp. 254-263, 2008.

[5] N. Herencsar, J. Koton, K. Vrba, and O. Cicekoglu, "Single UCC-N1B 0520 device as a modified CFOA and its application to voltage- and current-mode universal filters," In Proc. of the Int. Conf. on Applied Electronics - APPEL 2009, Pilsen, Czech Republic, pp. 127-130, 2009.

[6] N. Herencsar, J. Koton, and K. Vrba, "Voltage-mode universal filters employing single modified current feedback operational amplifier (MCFOA)," In Proc. of the 6th Int. Conf. on Electrical and Electronics Engineering - ELECO 2009, Bursa, Turkey, pp. 83-87, 2009.

[7] E. Yuce, "Fully integrable mixed-mode universal biquad with specific application of the CFOA," AEU-Int. J. Electron. and Commun., vol. 64, no. 4, pp. 304-309, 2010.

[8] J. A. Svoboda, L. McGory, and S. Webb, "Applications of a commercially available current conveyor," Int. J. Electronics, vol. 70, pp. 159164, 1991.

[9] A. Fabre, O. Saaid, F. Wiest, and C. Boucheron, "High frequency applications based on a new current controlled conveyor," IEEE Trans. Circuits and Systems-I, vol. 43, pp. 82-91, 1996.

[10] W. Chiu, S. I. Liu, H. W. Tsao, J. J. Chen, "CMOS differential difference current conveyors and their applications," IEE Proceedings-Circuits, Devices and Systems, vol. 144, no. 2, pp. 91-96, 1996.

[11] D. Becvar, K. Vrba, V. Zeman, and V. Musil, "Novel universal active block: a universal current conveyor," In Proc. of the IEEE Int. Symposium on Circuits and Systems - ISCAS 2000, Geneva, Switzerland, pp. 471-474, 2000.

[12] J. Cajka, T. Dostal, and K. Vrba, "General view on current conveyors," Int. J. of Circuit Theory and Applications, vol. 32, pp. 133-138, 2004.

[13] N. Herencsar and K. Vrba, "Current conveyors-based circuits using novel transformation method," IEICE Electron. Express, vol. 4, no. 21, pp. 650-656, 2007.

[14] J. Jerabek and K. Vrba, "SIMO type low-input and high-output impedance current- mode universal filter employing three universal current conveyors," AEU-Int. J. Electron. and Commun., vol. 64, no. 6, pp. 588-593, 2010 .

[15] A. Zeki and A. Toker, "The dual-X current conveyor (DXCCII): a new active device for tunable continuous-time filters," Int. J. Electronics, vol. 89, pp. 913-923, 2002.

[16] C. Acar and S. Ozoguz, "A new versatile building block: current differencing buffered amplifier suitable for analog signal processing filters," Microelectron. J., vol. 30, pp. 157-160, 1999.

[17] J. Koton, N. Herencsar, and K. Vrba, "KHN-equivalent voltage-mode filters using universal voltage conveyors," AEU-Int. J. Electron. and Commun., vol. 65, no. 2, pp. 154-160, 2011.

[18] R. L. Geiger and E. Sanchez-Sinencio, "Active filter design using operational transconductance amplifiers: A tutorial," IEEE Circuits Devices Mag., vol. 1, pp. 20-32, 1985. 
[19] D. Biolek, "CDTA - building block for current-mode analog signal processing," In Proc. of the 16th European Conf. on Circuit Theory and Design - ECCTD 2003, Krakow, Poland, pp. 397-400, 2003.

[20] R. Prokop and V. Musil, "Modular approach to design of modern circuit blocks for current signal processing and new device CCTA," In Proc. of the Seventh IASTED Int. Conf. on Signal and Image Processing - SIP 2005, Anaheim, USA, pp. 494-499, 2005.

[21] N. Herencsar, K. Vrba, J. Koton, and I. Lattenberg, "The conception of differential-input buffered and transconductance amplifier (DBTA) and its application," IEICE Electron. Express, vol. 6, pp. 329-334, 2009.

[22] N. Herencsar, J. Koton, and K. Vrba, "Realization of current-mode $\mathrm{KHN}$-equivalent biquad using current follower transconductance amplifiers (CFTAs)," IEICE Trans. Fundamentals, vol. E93-A, no. 10, pp. 1816-1819, 2010.

[23] U. E. Ayten, M. Sagbas, N. Herencsar, and J. Koton, "Novel floating general element simulators using CBTA," Radioengineering, vol. 21, no. 1, pp. 11-19, 2012.

[24] N. Herencsar, A. Lahiri, J. Koton, K. Vrba, and B. Metin, "Realization of resistorless lossless positive and negative grounded inductor simulators using single ZC-CCCITA," Radioengineering, vol. 21, no. 1, pp. 264 272, 2012.

[25] W. Surakampontorn and P. Thitimajshima, "Integrable electronically tunable current conveyors," IEE Proceedings-G, vol. 135, no. 2, pp. $71-77,1988$

[26] S. Minaei, O. K. Sayin, and H. Kuntman, "A new CMOS electronically tunable current conveyor and its application to current-mode filters," IEEE Trans. Circuits and Systems-I, vol. 53, pp. 1448-1457, 2006.

[27] N. Herencsar, A. Lahiri, K. Vrba, and J. Koton, "An electronically tunable current-mode quadrature oscillator using PCAs," Int. J. Electronics, vol. 99, no. 5, pp. 609-621, 2012.

[28] A. Fabre and N. Mimeche, "Class A/AB second-generation current conveyor with controlled current gain," Electron. Lett., vol. 30, no. 16, pp. 1267-1268, 1994.

[29] A. De Marcellis, G. Ferri, N. C. Guerrini, G. Scotti, V. Stornelli, and A. Trifiletti, "The VCG-CCII: a novel building block and its application to capacitance multiplication," Analog Integr. Circ. and Signal Process. vol. 58, no. 1, pp. 55-59, 2009.

[30] E. Yuce, K. Pal, and S. Minaei, "A high input impedance voltage-mode all-pass/notch filter using a single variable gain current conveyor," $J$ Circuits, Systems, and Computers, vol. 17, pp. 827-834, 2008.

[31] D. R. Frey, "Log-domain filtering: an approach to current mode filtering," IEE Proceedings-Circuits, Devices and Systems, vol. 140, no. 6 , pp. 406-416, 1993.

[32] N. Herencsar, J. Koton, K. Vrba, A. Lahiri, and B. Metin, "Novel dualmode electronically tunable all-pass filter using voltage gain-controlled MCFOA," In Proc. of the 13th Int. Conf. on Optimization of Electrical and Electronic Equipment - OPTIM 2012, Brasov, Romania, pp. 11991202, May 2012. DOI: 10.1109/OPTIM.2012.6231848

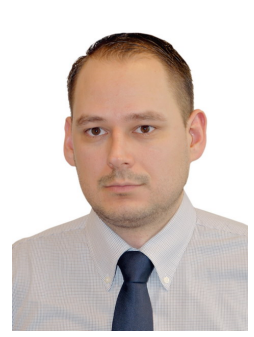

Norbert Herencsar received the M.Sc. and Ph.D. degrees in Electronics \& Communication and Teleinformatics from Brno University of Technology (BUT), Czech Republic, in 2006 and 2010, respectively. Currently, he is an Assistant Professor at the Department of Telecommunications, Faculty of Electrical Engineering and Communication, BUT. From September 2009 through February 2010 he was an Erasmus Exchange Student with the Department of Electrical and Electronic Engineering, Bogazici University, Istanbul, Turkey. His research interests include analog filters, current-mode circuits, tunable frequency filte design methods, and oscillators. $\mathrm{He}$ is an author or co-author of 25 research articles published in SCI-E international journals, 20 articles published in other journals, and 60 papers published in proceedings of international conferences. In 2011 and 2012, he received Rector Award in the University competition "Top 10 Excelence VUT" for the $9^{\text {th }}$ and $9^{\text {th }}$ most productive scientist at the BUT, category "Publications", respectively. Since 2008, Dr Herencsar serves in the organizing and technical committee of the Int. Conf on Telecommunications and Signal Processing (TSP). He is Senior Member of the IACSIT and Member of the IEEE, IAENG, and ACEEE.

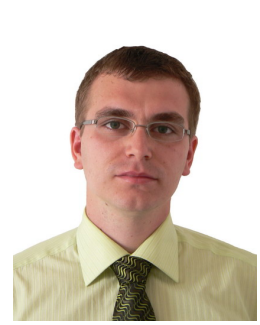

Jaroslav Koton received the M.Sc. an Ph.D. degree in electrical engineering from the Brno University of Technology, Czech Republic, in 2006 and 2009, respectively. He is currently an Assistant Professor at the Department of Telecommunications of the Faculty of Electrical Engineering and Communication of Brno University of Technology, Czech Republic. His current research is focused on linear- and nonlinear circuit designing methods with current or voltage conveyors, and current active elements. He is an author or co-author of about 125 research articles published in international journals or conference proceedings. Dr. Koton is a Member of IEEE and IACSIT.

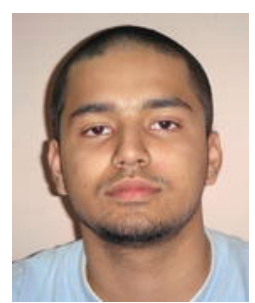

Abhirup Lahiri received Bachelor of Engineering (B.E.) degree with the highest honors from the Division of Electronics and Communications, Netaji Subhas Institute of Technology (erstwhile, Delhi Institute of Technology), University of Delhi, India. His past research works include design of compact analog circuit solutions using novel voltage-mode and current-mode active elements. His current research interests include low-power and low-voltage analog circuit design and precision voltage and current reference generation. He has authored/coauthored more than thirty international journal/conference papers (including fifteen SCI/SCI-E publications) and has acted as a reviewer (by editor's invitation) for numerous international journals and conferences of repute. He served as a program committee member for the International Conference on Telecommunications and Signal Processing (TSP). He is an editorial board member of Radioengineering Journal for the years 2011-2012. His biography is included in Marquis Who's Who in the World 2011- (28th Edition).

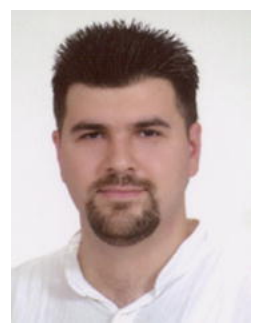

Bilgin Metin received the B.Sc. degree in Electronics and Communication Engineering from Istanbul Technical University, Istanbul, Turkey in 1996 and the M.Sc. and Ph.D. degrees in Electrical and Electronics Engineering from Bogazici University, Istanbul, Turkey in 2001 and 2007 respectively. He is currently an Assistant Professor in the Management Information Systems Department of Bogazici University. His research interests include continuous time filters, analog signal processing applications, current-mode circuits, and information systems. He was given the best student paper award of ELECO'2002 conference in Turkey. He has over 25 articles in SCI and SCI-E indexed journals and 25 conference proceedings.

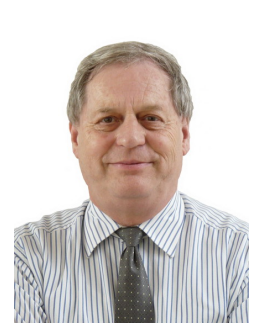

Kamil Vrba received the Ph.D. degree in Electrical Engineering in 1976, and the Prof. degree in 1997, both from the Technical University of Brno Since 1990 he has been Head of the Department of Telecommunications, Faculty of Electrical Engineering and Computer Science, Brno University of Technology, Brno, Czech Republic. His research work is concentrated on problems concerned with accuracy of analog circuits and mutual conversion of analog and digital signals. In cooperation with AM Semiconductor Czech, Ltd. (now ON Semiconductor Czech Republic, Ltd.) he has developed number of novel active function blocks for analog signal processing such as universal current conveyor (UCC), universal voltage conveyor (UVC), programmable current amplifier (PCA), digitally adjustable current amplifier (DACA), and others. He is an author or co-author of more than 700 research articles published in international journals or conference proceedings. Professor Vrba is a Member of IEEE and IEICE. 